\section{Adult polycystic kidney disease and intracranial aneurysms}

We describe for the first time a family whose three members all had adult polycystic kidney disease and intracranial aneurysms.

\section{Case reports}

Case 1-A 34 year old man presented in 1981 with accelerated hypertension. Renal ultrasonography confirmed that he had polycystic kidneys. In 1985 he was admitted with a subarachnoid haemorrhage. Neurosurgery showed a right cerebral haematoma, probably from an intracranial aneurysm. This was evacuated, but he died soon afterwards.

Case 2-A 39 year old woman, the sister of the patient in case 1, presented in 1978 with a subarachnoid haemorrhage. Cerebral arteriography showed bilatera intracranial aneurysms, but she was managed conservatively. In 1983 intravenous pyelography showed that she had polycystic kidneys. In 1986 she had a prolonged grand mal fit, and subsequently her renal function deteriorated. She was referred for continuous ambulatory peritoneal dialysis and remained well.

Case 3-A 36 year old man, the brother of the patients in cases 1 and 2 , presented in 1978 with haematuria. Intravenous urography showed that he had polycystic kidneys. In 1986 his family history became known and he underwent elective cerebral digital subtraction angiography, which showed an aneurysm 6 $\mathrm{mm}$ in diameter of the right middle cerebral artery (figure). This was clipped, and he remained well.

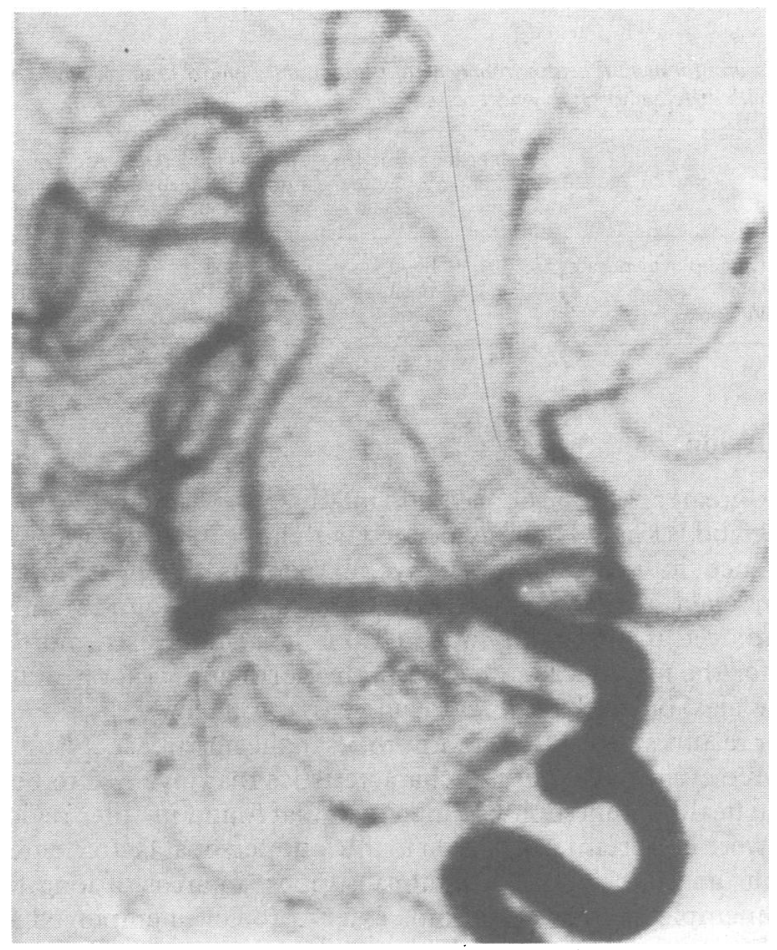

Cerebral digital subtraction angiography showing aneurysm at trifurcation of right middle cerebral artery.

\section{Comment}

The association between intracranial aneurysms and adult polycystic kidney disease is well recognised. Recently, it has been suggested that patients with polycystic kidneys and a family history of intracranial aneurysms or subarachnoid haemorrhage have a greater risk of having aneurysms themselves than those without such a family history, ${ }^{1}$ and our cases support this.

The risk of rupture of intracranial aneurysms has been estimated at $2 \%$ a year, ${ }^{2}$ and once rupture has occurred the prognosis, short term and long term, is poor. ${ }^{3}$ The outcome of surgery for unruptured aneurysms, however, is excellent. ${ }^{4}$ For these reasons the need to screen for intracranial aneurysms in patients with polycystic kidneys has been emphasised. ${ }^{5}$ Two such studies have been performed in Japan. Wakabayashi et al found seven patients with aneurysms among 17 with polycystic disease from 10 different families ${ }^{5}$ Five of these underwent surgery without complications. Similarly, Matsumara et al performed cerebral angiography on five patients with polycystic kidneys and found that three had aneurysms. ${ }^{4}$ Two of these underwent surgery successfully.

Routine screening for intracranial aneurysms in people with polycystic kidneys, however, poses some problems. Firstly, there is no simple, noninvasive screening method. At present, the only sensitive method for detecting small aneurysms is cerebral arteriography, ${ }^{2}$ and although complications are rare, they are potentially devastating. The advent of digital subtraction angiography has improved the situation only marginally since arterial injections of contrast are still necessary to achieve the resolution required to detect small aneurysms. Secondly, the optimum age at which to screen has not been defined, and it is by no means certain that a patient who has undergone angiography and been found not to have aneurysms will not develop aneurysms later.

For these reasons screening all patients with polycystic kidneys for intracranial aneurysms may not be worth while unless a subgroup at higher risk of having aneurysms can be identified. The only possible subgroup at present seems to be patients with a family history of intracranial aneurysms or subarachnoid haemorrhage, and we therefore suggest that these patients should be investigated.

1 Kaehny W, Bell P, Earnest M, Stears J, Gabov P. Familial clustering of intracranial aneurysms in autosomal dominant polycystic kidney disease. Abstract from American Society of Nephrology. autosomal dominant polycy

2 Levey AS, Pauker SG, Kassirer JP. Occult intracranial aneurysms in polycystic kidney disease. When is cerebral arteriography indicated? N Engl f Med 1983;308:986-94.

3 Nishioka H, Torner JC, Graf CJ, Kassell NF, Sahs AL, Goettler LC. Cooperative study of intracranial aneurysms and subarachnoid haemorrhage; a long term prognostic study. II. Ruptured intracranial aneurysms managed conservatively. Arch Neurol 1984;41:1142-6.

4 Matsumara $M$, Wada H, Ohwada A, Shinoda T. Unruptured intracranial aneurysms and polycystic kidney disease. Acta Neurochir (Wien) 1986;79:94-9.

5 Wakabayashi T, Fujita S, Ohbora Y, Suyama T, Tamaki N, Matsumoto S. Polycystic kidney disease and intracranial aneurysms. Early angiography diagnosis and early operation for the unruptured aneurysm. I Neurosurg 1983;58:488-91.

(Accepted 3 fune 1987)

Royal South Hampshire Hospital, Southampton SO9 4PE

A SAIFUDDIN, BSC, $\mathrm{MB}$, senior house officer in general medicine

J R E DATHAN, MD, FRCP, consultant physician

Correspondence to: Dr Dathan.

\section{Drug abuse: a new problem}

There have been many reports relating to aspects of drug abuse. Over the past two years we have witnessed a new hazard-namely, children presenting to hospital with needlestick injuries from discarded, used needles found in public places. We report one incident, review our total caseload, and recommend a policy for treating this problem.

\section{Case reports}

In May 1985 three children (aged 3-4) found a used $2 \mathrm{ml}$ syringe and needle in a local dump known to be frequented by drug addicts. All three children stabbed themselves with the needle. They presented within 12 hours to hospital and received local toilet to their wounds. Blood eluted from the syringe and needle was tested for hepatitis B virus and antibody to human immunodeficiency virus (HIV). While awaiting these results the children were given hepatitis B immunoglobulin. The blood from the syringe and needle proved positive for hepatitis B surface antigen (HBsAg) but negative for antibody to HIV. The children were given a course of hepatitis $B$ vaccine. Subsequently, they developed antibodies to $\mathrm{HBsAg}$, proving uptake of the vaccine; none became clinically infected.

From June 1985 to April 1987, 15 further children (13 incidents) presented to our hospital. Most of these occurred after January 1987. In all cases the syringes and needles were available for analysis but none proved positive for either $\mathrm{HBsAg}$ or HIV antibodies.

\section{Comment}

These cases illustrate an ever increasing problem. From previous reports of the infectivity, diagnosis, and treatment of infections with hepatitis B 
virus and HIV we have formulated a policy to deal with it. In western Europe only $0 \cdot 1-0 \cdot 5 \%$ of the population are carriers of hepatitis B virus. Chronic carriage among intravenous drug abusers is much higher. The risk of acquiring infection with hepatitis $B$ virus after injury from an infected needle ranges from $6 \%$ to $30 \% .^{1}$ Infectivity depends on the concomitant presence of hepatitis B e antigen. ${ }^{2}$ The prevalence of HIV in the general population is much lower than that of hepatitis B virus, but again drug abusers are an at risk group. Although the risk of acquiring infection with HIV after an injury from a needle with the virus is less than $1 \%,{ }^{1}$ it is not negligible. ${ }^{3}$

Most hospital laboratories can test for or refer for testing for $\mathrm{HBsAg}$ and HIV antibodies, and results should be available within four hours. Although no treatment exists for infection with HIV, preventing infection with hepatitis $B$ virus by immunisation is possible. For passive immunity to be successful hepatitis B immunoglobulin should be administered within 48 hours. ${ }^{4}$ Its supply is limited at present, and it should therefore be reserved when possible for identified cases. Producing active immunity by hepatitis $B$ vaccination is also an effective means of prevention, particularly when vaccine is given early. ${ }^{5}$ We used both forms of immunisation.

Similar problems should be dealt with as follows. The nature and time of the needlestick injury should be noted. If the needle and syringe are available screening tests should be performed. If time permits no treatment is required until the results are known. If the results of screening are positive for hepatitis B virus, the needle and syringe are not available, or time does not permit the patient should be immunised against hepatitis $B$. If results are positive for HIV the patient should be followed up, though no treatment can be offered.

1 Centers for Disease Control. Recommendations for preventing transmission of HTLV III in the workplace. $M M W R$ 1985;34:22-32.

2 Shikata T, Karasawa T, Abe K, et al. Hepatitis B e antigen and infectivity of hepatitis B virus. F Infect Dis 1977;136:571-6.

3 Anonymous. Needlestick transmission of HTLV III from a patient infected in Africa. [Editorial.] Lancet 1984;ii:1376-7.

4 Reesink HW, Reerink-Brongers EE, Lafeber-Schul BJ, et al. Prevention of chronic HBsAg carrier state in infants of HBsAg positive mothers of hepatitis B immunoglobulin. Lancet 1979;ii:436-8. 5 Szumness W, Stevens CE, Harley EJ, et al. Hepatitis B vaccine: demonstration of efficacy in a controlled clinical trial in a high risk population in the United States. N Engl f Med 1980;303: 833-41.

(Accepted 29 June 1987)

Royal Liverpool Children's Hospitals

S S WALSH, MRCPI, DCH, registrar, accident and emergency department

A $M$ PIERCE, $M B, C H B$, locum consultant, accident and emergency department C A HART, MB, MRCPATH, professor of medical microbiology

Correspondence to: Dr S S Walsh, Royal Liverpool Children's Hospital (Alder Hey), Eaton Road, Liverpool 12.

\section{Disposal of plastic insulin syringes and needles}

Plastic insulin syringes will be available free on prescription from 1 September. The government has costed this exercise on the basis of "single use only." Local authorities have recently expressed concern about disposal methods, largely because of the acquired immune deficiency syndrome. For many years diabetics treated with insulin have been using, reusing, and disposing of plastic syringes without any reported problems. We surveyed 179 patients to ascertain their methods of disposing of syringes and their attitude to reusing them if they were made available free.

\section{Methods and results}

Patients were asked: (a) How do you dispose of your syringes, needles, and other "sharps"? (b) Do you think your method of disposal is safe? (c) Do you think you should be provided with disposal bins for sharps? (d) When syringes become available free on prescription will you change your frequency of reuse?

Methods of disposing of insulin syringes, needles, and other sharps-All 179 patients replaced the guard on the needle before disposal. Altogether 139 patients (78\%) disposed of their syringes in the household waste, which was then put into either a dustbin or a refuse disposal bag; 19 put them into a sealed tin or jar before disposal; eight used special sharps disposal bins; six incinerated them; and seven used other, more individual methods. These other methods included burial in concrete, long term storage in a drawer, obsessional wrapping in sealed parcels, and using syringes as floats and for dispersing bait for fishing (two people). In areas where plastic bags rather than dustbins were used people were conscious of the risk of foxes scattering the rubbish and therefore took extra care to disguise their syringes.
Safety of method of disposal -Altogether 139 patients considered their method of disposal to be safe. Forty patients were not entirely happy but saw no practical alternative: 32 were concerned about possible illicit reuse by intravenous drug abusers and only eight had considered that there might be a risk of needle stick injury. Because they did not consider themselves to be at high risk for the acquired immune deficiency syndrome they did not think that their syringes would be a risk to others.

Provision of disposal bins for sharps-Three quarters of the patients thought the provision of special bins a reasonable idea, although they were not convinced of its necessity; the remaining quarter thought it totally unnecessary. Asked whether they would be prepared to pay for such bins at a cost of $£ 1.50$ every six months, 72 patients said that they would not.

Reuse of syringes obtained free on prescription-Altogether 154 patients said that they would continue to reuse their syringes; the remaining 25 said that they would use them only once.

\section{Comment}

fin estimated 250000 diabetics receiving insulin have been reusing their plastic syringes and disposing of them for many years. We calculate that at least 11 million syringes and needles have therefore been disposed of every year in the household waste. Despite the presence of highly infectious agents, such as staphylococci and the hepatitis B antigen, no serious cases of transmitted infection have been reported. There have been occasional reports of minor injury from miscellaneous sharp objects and alarm at the discovery of syringes.

Is concern now justified? Human immunodeficiency virus is not easily transmitted. ' The vast majority of diabetics are negative for human immunodeficiency virus so their needles should present no risk. We therefore think that current disposal methods are safe and that concern is illogical and unnecessary. Clearly, however, patients positive for human immunodeficiency virus and hepatitis B should be provided with disposal bins for sharps.

In view of the figures for reuse of syringes we suggest that the government's costing is an overestimate. Perhaps the surplus could be put towards making blood glucose monitoring strips available free.

1 McEvoy M, Mortimer P, Shanson D, et al. Prospective study of clinical and ancillary staff with accidental exposure to blood or body fluids from patients infected with human immunodeficiency virus. Communicable Disease Report (in press).

(Accepted 21 fuly 1987)

Queen Mary's Hospital, Sidcup DA14 6LT

WILLIAM D ALEXANDER, MB, MRCP, consultant physician

C CORRIGAN, MA, MRCP, senior house officer

P TODD, MB, MRCP, senior house officer

M WELLS, SRN, diabetes nurse specialist

Correspondence to: Dr Alexander.

\section{Diuresis and syncope after renal angioplasty in a patient with one functioning kidney}

Percutaneous transluminal angioplasty is a widely accepted treatment for renal artery stenosis, offering a viable alternative to reconstructive surgery. ${ }^{1}$ The percutaneous approach may be the treatment of choice when the risks of surgery are considered to be unacceptable. The complications of this procedure include retroperitoneal haemorrhage, dissection of the renal artery, embolisation of dislodged fragments, and immediate profound hypotension.

We report a further complication: postural hypotension and syncope after a considerable postangioplasty diuresis.

\section{Case history}

A 74 year old man presented with a mild left hemiparesis in 1983, when his blood pressure was $220 / 130 \mathrm{~mm} \mathrm{Hg}$. Thirty years previously tec had apparently undergone a series of operations to remove large calculi from both kidneys. There was clinical evidence of peripheral vascular disease. He had been a heavy smoker and had poor respiratory reserve. His serum creatinine concentration was increased at $190 \mu \mathrm{mol} / \mathrm{l}$, with a creatinine clearance of $11 \mathrm{ml} / \mathrm{min}$. In the outpatient clinic his blood pressure was difficult to control; he was able to tolerate only slow release nifedipine $20 \mathrm{mg}$ twice daily and clonidine $50 \mu \mathrm{g}$ three times daily. His serum creatinine concentration slowly rose to $220 \mu \mathrm{mol} / \mathrm{l}$. 